Harold A. McAlister and William I. Harkopf (eds.)

\title{
Spectroscopic Studies of Multiple Stars and Speckle Binaries: How to observe ad infinitum
}

\author{
FRANCIS C. FEKEL ${ }^{1}$ \\ NASA Marshall Space Flight Center, Huntsville, AL 35812, USA
}

\begin{abstract}
Over the past 16 years at the McDonald Observatory and the Kitt Peak National Observatory, I have obtained high-dispersion spectroscopic observations of roughly 3 dozen multiple systems and 7 speckle or astrometric binaries. The current status of this obviously long-term project is discussed. Although some systems have periods of about 50 to 85 years, most have periods in the range of 1 to 20 years. Thus, many now have been observed for at least one cycle and preliminary spectroscopic orbital elements have been determined. For a number of the systems fundamental data such as the distance to the system, as well as the individual spectral types, absolute magnitudes, and masses can be obtained if accurate visual/speckle orbital elements also are known. These elements and the derived fundamental parameters may be used as constraints on multiple-star formation theory.
\end{abstract}

\section{INTRODUCTION}

As a graduate student, my observing list for my first observing run at the McDonald Observatory consisted of about 3 stars that I observed over and over again. One of the stars, $\psi \mathrm{Sgr}$, was for my master's thesis and the other two were similar systems that I found in the literature. At the time, I naïvely wondered how one could ever find enough stars of interest to fill up an observing program. Now of course, I have observing lists for 4 or 5 projects that consist of a total of more than several hundred stars. Even with a long observing run and completely clear weather, I can not observe all of my stars. In addition the observation of some stars requires excellent seeing conditions while others can be done under horrible weather conditions (such as those on my last Kitt Peak run in December) when all other optical telescopes on the mountain are closed.

The objective of that first observing run was to obtain spectrograms of close multiple systems. In the present context "close" means separations at most of a few tenths of an arcsec so that the stellar image seen at the slit of the spectrograph appears to be that of a single star. Analysis of these plates was to result in the determination of orbital elements and the fundamental parameters of the components with the hope that such results could eventually be compared with binary and multiple-star formation theory. As all of you in this business know, many of these systems are the work of a lifetime or more as exemplified by the work of Van Biesbroeck (1974), whose untimely death at the age of 94 cut short a great observing career! In my case, $\psi \mathrm{Sgr}$, my first star, has an orbital period of about 20 years. Thus, I am only now finishing my observations of one orbital period on the system that started it all. From that small beginning, my program has expanded to include nearly three dozen close multiple-star

\footnotetext{
${ }^{1}$ Visiting Astronomer, Kitt Peak National Observatory, National Optical Astronomy Observatories, operated by the Association of Universities for Research in Astronomy, Inc., under contract with the National Science Foundation.
} 
systems and over a half dozen visual and/or speckle interferometric binaries. Although the program has concentrated on late-type stars because they are generally slowly rotating, some early-type systems have been observed. Many of the systems that I have identified have been passed along to the CHARA group at Georgia State University so that complementary speckle observations can be obtained.

\section{OBSERVATIONS AND REDUCTIONS}

Between 1973 and 1981, I obtained spectroscopic observations of these systems at the McDonald Observatory with the 2.1-m telescope, coude spectrograph, and photographic plates. After 1976, most of the observations at McDonald were obtained with the, then, newly developed Reticon solid-state detector (Vogt, Tull, \& Kelton 1978), the coudé spectrograph, and the 2.7-m telescope. From 1982 to the present some of the observations were obtained with the Kitt Peak National Observatory's (KPNO) coudé feed telescope, coudé spectrograph, and photographic plates, but the vast majority were obtained with that telescope and spectrograph system and various charge coupled devices (CCD's).

Since I have not used echelle-spectrograph systems but require relatively high resolution of about $0.2 \AA$ to at least partially resolve the spectral features, only a small wavelength region, typically $80 \AA$ or less, can be observed at any one time with the currently available CCD's (This may change in the near future with the advent of 3000 pixel Ford CCD's.). Thus, great care must be taken in choosing an appropriate wavelength region. Although Griffin-type radialvelocity instruments and CORAVEL work best when wavelength regions that contain a large number of lines are observed, such regions are not the best for my particular setup. However, the lack of a large number of lines is compensated by the high signal-to-noise (S/N) capability of CCD's. Thus, to detect the weak and/or broad lines in the spectrum of a close multiple star, one would ideally need a relatively uncluttered wavelength region that contains a modest number (say a half dozen) of moderate strength (equivalent widths of say 100 to 200 $\mathrm{m} \AA$ ) lines. With these constraints in mind, two regions have been chosen, one centered at $4500 \AA$ for late-B stars and A stars and the other centered at 6430 $\AA$ for late-A through $K$ stars.

Because only a small portion of the spectrum is observed and many of the components of a double, triple, or quadruple system appear in the spectrum as quite weak lines (say 2 or $3 \%$ deep) as a result of the superposition of the their continua, the technique of cross correlation does not necessarily provide accurate velocities of the weak components. Thus, a somewhat different approach has been used. A program, originally written by Lacy (Fekel, Bopp, \& Lacy 1978), has been modified and used to determine the radial velocities. The spectrum of the program star is examined and the the best lines (least blended, most symmetric, etc. ) are summed together to give a single profile. The same lines are summed for a reference star of similar spectral type whose velocity is assumed known. The minimum of each profile is determined and the velocity shift between the program and reference star minima is determined. The heliocentric-velocity correction for both stars is applied and the velocity difference is adjusted for the velocity of the reference star to give the final velocity of 
that component of the program star. The same or a different set of lines may be summed together depending on line blending to determine the velocity of a second or third component of the program star. Typically, a radial velocity is determined from the summed profile of about four to six lines if the lines are narrow and relatively strong while a velocity may be determined from as few as one or two lines if the lines of that component are weak and/or broad.

At the inception of this project, the list of IAU radial-velocity standard stars contained only stars of spectral type F5 or later (Pearce 1957). With the advent of solid-state detectors and cross-correlation techniques, it became important to identify a number of narrow lined constant-velocity early-type stars that could be used as reference stars. Thus, I began to observe about 40 candidate stars with spectral types $B$ through early $F$ that appeared to have constant velocity. A status report on this work was presented to Commission 30 of the IAU (Latham \& Stefanik 1992).

\section{GENERAL DISCUSSION}

Table 1 lists 33 close multiple stars, 6 speckle binaries, and 1 astrometric binary. Columns 1 and 2 list the system's name and double star name. Superscripts indicate whether a paper has already been published on a system or whether the results are currently being written up for publication. Even if a paper is not in preparation, an orbit may have been computed for the system (Table 2). Column 3 lists the system's $V$ magnitude while column 4 gives the best spectral types for the components, some of which differ significantly from those given in the literature. Many of the types have been determined from my spectrograms with the method of spectrum addition (Strassmeier \& Fekel 1990). Column 5 lists the total number of known components in the close system and the number of those components whose lines have been detected in the spectrograms, even if the lines of a component are too broad to be measured accurately for radial velocities. Column 6 and 7 list, respectively, the long orbital period in years and the short orbital period in days. An " $\mathrm{e}$ " indicates that the system is eclipsing. Column 8 gives the range of years that the system has been observed. In most cases observations of a system have continued even after publication of a paper but in several cases, such as $\lambda$ Tau and $\chi$ Dra, no additional observations have been obtained.

Table 2 lists the "long-period" spectroscopic elements for 11 multiple-star systems and 5 binaries in Table 1 . For all but $\eta$ Vir and perhaps HD 202908, additional observations are not expected to change the elements significantly although the uncertainties of the elements will certainly be reduced. In about half of the cases visual orbital elements are available for comparison with the spectroscopic results and in most cases the agreement is quite good. 
TABLE 1. Multiple stars and speckle binaries.

\begin{tabular}{|c|c|c|c|c|c|c|c|}
\hline Name & Double Star & V & $\begin{array}{l}\text { Spectral } \\
\text { Type }\end{array}$ & $\begin{array}{c}\text { Total/ } \\
\text { Vis }\end{array}$ & $\begin{array}{c}P_{L} \\
(\mathrm{yr})\end{array}$ & $\underset{\text { (days) }}{P_{s}}$ & $\begin{array}{l}\text { Years } \\
\text { Obs'd }\end{array}$ \\
\hline 13 Cet & ADS 490 & 5.2 & F7V,G4V & $3 / 2$ & 6.95 & 2.1 & 15 \\
\hline HR266 ${ }^{1}$ & ADS 784 & 5.6 & $\begin{array}{l}\text { B7IV,B9IV, } \\
\text { A1V }\end{array}$ & $4 / 3$ & 83.1 & $\begin{array}{r}4.24 \\
1769\end{array}$ & 16 \\
\hline HR763 & McA 7 & 5.7 & F7V,F7V & $2 / 2$ & - & 694 & 14 \\
\hline$\tau$ Per & & 3.9 & A2V,G8III ${ }^{18}$ & $2 / 2$ & - & $1516 e$ & 11 \\
\hline$\lambda \operatorname{Tau}^{2}$ & & 3.5 & B3V,A4 & $3 / 2$ & 0.09 & 3.95 & 2 \\
\hline HR1455 & & 6.4 & F6IV,G8III ${ }^{10}$ & $3 / 2$ & 1.33 & 4.5 & 5 \\
\hline HR1458 3 & CHARA 18 & 4.2 & A8m & $5 / 5$ & 30: & 3.57 & 8 \\
\hline$\alpha$ Aur & & 0.1 & G1III,K0III ${ }^{20}$ & $2 / 2$ & - & 104 & 12 \\
\hline$\mu \mathrm{Ori}^{*}$ & ADS 4617 & 4.1 & $\begin{array}{l}\text { A8m } \\
\text { F7V,F7V }\end{array}$ & $4 / 3$ & 18.9 & $\begin{array}{l}4.45 \\
4.78\end{array}$ & 13 \\
\hline $64 \mathrm{Ori}^{b}$ & McA 24 & 5.1 & $\begin{array}{l}\text { B5V,B7V, } \\
\text { B8V }\end{array}$ & $3 / 3$ & 13.0 & 14.57 & 15 \\
\hline $1 \mathrm{Gem}$ & Kui 23 & 4.2 & F6IV,K1III ${ }^{10}$ & $3 / 2$ & 13.4 & 9.60 & 16 \\
\hline HR2236 & Rst 5225 & 6.4 & F5,F5,F5 & $3 / 3$ & 30.2 & 2.19 & 5 \\
\hline $\boldsymbol{\gamma}$ Gem & & 1.9 & A0IV & $2 / 1$ & - & 4612 & 13 \\
\hline $63 \mathrm{Gem}$ & McA 30Aa & 5.2 & F6,F6,F9 & $3 / 3$ & 2.1 & 1.93 & 7 \\
\hline HR3337 & ADS 6828 & 6.4 & $\begin{array}{l}\mathbf{A} 5 \mathrm{~m}, \mathbf{F} \\
\mathbf{A}, \mathbf{F}\end{array}$ & $4 / 4$ & 52.6 & $\begin{array}{l}2.50 \mathrm{e} \\
5.98\end{array}$ & 15 \\
\hline HR3551 & Fin 316 & 5.3 & A9IV & $3 / 3$ & 7.2 & 9.07 & 15 \\
\hline $20 \mathrm{Leo}^{\circ}$ & Kui 44 & 6.1 & $\begin{array}{l}\text { A8IV,A8IV, } \\
\text { A8IV }\end{array}$ & $3 / 3$ & $?$ & 24.15 & 5 \\
\hline HD86590 & CHARA145 & 7.8 & $\begin{array}{l}\text { K2V,K5V, } \\
\text { K5V } 10\end{array}$ & $3 / 3$ & $?$ & 1.07 & 7 \\
\hline p Vel & See 119 & 3.8 & $\mathbf{A m}, \mathbf{F}, \mathbf{A} \mathbf{6}$ & $3 / 3$ & 16.3 & 10.21 & 11 \\
\hline$\eta \mathrm{Vir}^{7}$ & McA 37 & 3.9 & A2IV,A4V & $3 / 3$ & 13.1 & 71.79 & 13 \\
\hline $\begin{array}{l}\text { DL Vir }{ }^{8} \\
\text { HD131861 }\end{array}$ & & $\begin{array}{l}6.5 \\
7.6\end{array}$ & $\begin{array}{l}\text { A2V,KOIII }{ }^{18} \\
\text { F5V,GV }\end{array}$ & $\begin{array}{l}3 / 2 \\
3 / 2\end{array}$ & $\begin{array}{l}6.2 \\
5:\end{array}$ & $\begin{array}{l}1.32 e \\
3.55\end{array}$ & $\begin{array}{r}16 \\
7\end{array}$ \\
\hline HR6469 & McA 47 & 5.5 & F2V,G5IV ${ }^{10}$ & $3 / 2$ & 5.5 & $2.23 e$ & 12 \\
\hline HR6497 & & 6.1 & $\mathrm{~A} 0, \mathbf{A} 0, \mathrm{~K}_{0} \mathrm{III}^{\mathbf{1 8}}$ & $3 / 3$ & 3.3 & 3.76 & 16 \\
\hline HR6697 ${ }^{10}$ & McA 50 & 6.3 & G2V,KV & $2 / 2$ & - & 882 & 5 \\
\hline HD165590 11 & ADS 11060 & 7.1 & GOV,G5V ${ }^{10}$ & $3 / 2$ & 20.3 & $0.88 e$ & 15 \\
\hline$\chi$ Dra $^{12}$ & & 3.6 & F7V,G8V & $2 / 2$ & - & 281 & 4 \\
\hline HD172743 & ADS 11574 & 7.8 & A8V & $3 / 3$ & 52. & $?$ & 10 \\
\hline HD174343 & ADS 11698 & 7.2 & F5V,F5V & $3 / 2$ & $?$ & 4.24 & 16 \\
\hline$\psi \mathrm{Sgr}^{13}$ & ADS 12214 & 4.8 & $\begin{array}{l}\text { A9V,A9III, } \\
\text { KoIII }{ }^{10}\end{array}$ & $3 / 3$ & 20.0 & 10.78 & 18 \\
\hline$\phi \mathrm{Cyg}$ & McA 57 & 4.7 & KoIII,KOIII ${ }^{18}$ & $2 / 2$ & - & 434.1 & 1 \\
\hline$\beta \mathrm{Cap}^{14}$ & & 3.1 & B8V,K0III & $3 / 2$ & 3.8 & 8.68 & 3 \\
\hline GL $815^{16}$ & Kui 103 & 10.1 & $\begin{array}{l}\text { M2V,M4V, } \\
\text { M4V }\end{array}$ & $3 / 3$ & 29.3 & 3.28 & 2 \\
\hline HD202260 & ADS 14775 & 7.5 & A1V & $3 / 3$ & 78.4 & ? & 6 \\
\hline HD202908 ${ }^{16}$ & ADS 14839 & 7.1 & $\begin{array}{l}\text { F9V,G0V, } \\
\text { G1V }\end{array}$ & $3 / 3$ & 77.2 & 3.97 & 16 \\
\hline HD203345 & ADS 14893 & 6.7 & $\begin{array}{l}\text { F7V,F8V, } \\
\text { G8V }\end{array}$ & $3 / 3$ & 6.0 & 2.23 & 15 \\
\hline 42 Cap & & 5.2 & G0V,G1V & $3 / 2$ & $?$ & 13.2 & 4 \\
\hline 77 Cyg & Kui 108 & 5.7 & $\mathrm{AOV}, \mathrm{A} O \mathrm{~V}$ & $3 / 3$ & 26.8 & 1.73 & 8 \\
\hline HR8704 & McA 73 & 5.8 & B8,B9,A1 & $3 / 3$ & 20: & $\mathbf{3 . 4 3}$ & 8 \\
\hline HD221264 & ADS 16800 & 7.4 & $\begin{array}{l}\text { F6V,F9V } \\
\text { F7V,F8V }\end{array}$ & $4 / 4$ & 48.8 & $\begin{array}{r}1.92 \\
13.04\end{array}$ & 17 \\
\hline
\end{tabular}


TABLE 1. (continued)

\begin{tabular}{|c|c|c|c|}
\hline $\begin{array}{l}1 \\
2 \\
3 \\
: \\
: \\
:\end{array}$ & $\begin{array}{l}\text { Cole et al. (1992) } \\
\text { Fekel \& Tomkin (1982) } \\
\text { Willmitch (1989) } \\
\text { Fekel (1980) } \\
\text { Fekel \& Scarfe (1986) } \\
\text { Fekel \& Bopp (1977) } \\
\text { Hartkopf et al. (1992) } \\
\text { Fekel, in preparation } \\
\text { Scarfe et al. (1992) } \\
\text { Culver et al., in preparation }\end{array}$ & $\begin{array}{l}11 \\
12 \\
13 \\
14 \\
16 \\
16 \\
17 \\
18 \\
10\end{array}$ & $\begin{array}{l}\text { Batten et al. (1979) } \\
\text { Tomkin et al. (1987) } \\
\text { Fekel (1975) } \\
\text { Evans \& Fekel (1979) } \\
\text { Fekel et al. (1978) } \\
\text { Fekel (1981b) } \\
\text { Willmitch \& Fekel (1990) } \\
\text { Fekel, unpublished } \\
\text { Strassmeier \& Fekel (1990) }\end{array}$ \\
\hline
\end{tabular}

TABLE 2. Orbital elements

\begin{tabular}{|c|c|c|c|c|c|c|c|}
\hline Name & $\begin{array}{c}\text { Double } \\
\text { Star }\end{array}$ & $\underset{\text { (years) }}{\mathbf{P}}$ & $\begin{array}{c}\mathbf{T} \\
\text { (years) }\end{array}$ & e & $\stackrel{\omega}{(\operatorname{deg})}$ & $\begin{array}{c}\gamma \\
(\mathrm{km} / \mathrm{s})\end{array}$ & $\begin{array}{c}K \\
(\mathrm{~km} / \mathrm{s})\end{array}$ \\
\hline 13 Cet B & $\begin{array}{l}\text { ADS } 490 \\
\text { Ho } 212 \mathrm{AB}\end{array}$ & $\begin{array}{r}6.957 \\
\pm 0.024\end{array}$ & $\begin{array}{r}1987.175 \\
\pm 0.016\end{array}$ & $\begin{array}{r}0.776 \\
\pm 0.021\end{array}$ & $\begin{array}{r}286.1 \\
\pm 2.1\end{array}$ & $\begin{array}{r}9.1 \\
\pm 0.2\end{array}$ & $\begin{array}{r}16.3 \\
\pm 1.0\end{array}$ \\
\hline 31 Ari A & McA 7 & $\begin{array}{r}1.9011 \\
\pm 0.0001\end{array}$ & $\begin{array}{r}1986.236 \\
\pm 0.001\end{array}$ & $\begin{array}{r}0.754 \\
\pm 0.002\end{array}$ & $\begin{array}{r}121.9 \\
\pm 0.5\end{array}$ & $\begin{array}{r}8.3 \\
\pm 0.1\end{array}$ & $\begin{array}{r}20.7 \\
\pm 0.1\end{array}$ \\
\hline T Per A & & $\begin{array}{r}4.1502 \\
\pm 0.0001\end{array}$ & $\begin{array}{r}1988.993 \\
\pm 0.002\end{array}$ & $\begin{array}{r}0.732 \\
\pm 0.004\end{array}$ & $\begin{array}{r}233.4 \\
\pm 0.2\end{array}$ & $\begin{array}{r}1.6 \\
\pm 0.1\end{array}$ & $\begin{array}{r}19.0 \\
\pm 0.2\end{array}$ \\
\hline $\begin{array}{l}\text { Capella } \\
\text { (G1III) }\end{array}$ & & $\begin{array}{r}104.022 \\
\pm 0.008\end{array}$ & - & $\underline{0.0}$ & - & $\begin{array}{r}27.5 \\
\pm 0.4\end{array}$ & $\begin{array}{r}29.5 \\
\pm 0.1\end{array}$ \\
\hline$\mu$ Ori A & $\begin{array}{l}\text { ADS } 4617 \\
\text { A } 2715\end{array}$ & $\begin{array}{r}18.935 \\
\pm 0.038\end{array}$ & $\begin{array}{r}1985.018 \\
\pm 0.027\end{array}$ & $\begin{array}{r}0.737 \\
\pm 0.009\end{array}$ & $\begin{array}{r}32.1 \\
\pm 1.5\end{array}$ & $\begin{array}{r}42.3 \\
\pm 0.1\end{array}$ & $\begin{array}{l}14.3 \\
\pm 0.4\end{array}$ \\
\hline 1 Gem A & Kui 23 & $\begin{array}{r}13.359 \\
\pm 0.041\end{array}$ & $\begin{array}{r}1982.421 \\
\pm 0.038\end{array}$ & $\begin{array}{r}0.382 \\
\pm 0.008\end{array}$ & $\begin{array}{r}20.9 \\
\pm 1.3\end{array}$ & $\begin{array}{l}25.1 \\
\pm 0.1\end{array}$ & $\begin{array}{r}11.4 \\
\pm 0.1\end{array}$ \\
\hline$\gamma \operatorname{Gem} A$ & & $\begin{array}{r}12.628 \\
\pm 0.004\end{array}$ & $\begin{array}{r}1991.965 \\
\pm 0.008\end{array}$ & $\begin{array}{r}0.896 \\
\pm 0.003\end{array}$ & $\begin{array}{r}312.2 \\
\pm 1.6\end{array}$ & $\begin{array}{l}-12.0 \\
\pm 0.2\end{array}$ & $\begin{array}{r}11.9 \\
\pm 0.2\end{array}$ \\
\hline $63 \mathrm{Gem} B$ & McA $30 \mathrm{As}$ & $\begin{array}{r}2.090 \\
\pm 0.003\end{array}$ & $\begin{array}{r}1986.016 \\
\pm 0.005\end{array}$ & $\begin{array}{r}0.430 \\
\pm 0.006\end{array}$ & $\begin{array}{r}14.3 \\
\pm 1.3\end{array}$ & $\begin{array}{r}22.4 \\
\pm 0.1\end{array}$ & $\begin{array}{r}28.8 \\
\pm 0.3\end{array}$ \\
\hline$\eta \operatorname{Vir} A$ & McA 37 & $\begin{array}{r}12.9 \\
\pm 0.4\end{array}$ & $\begin{array}{r}1964.5 \\
\pm 0.9\end{array}$ & $\begin{array}{r}0.24 \\
\pm 0.06\end{array}$ & $\begin{array}{r}8.9 \\
+13.4\end{array}$ & $\begin{array}{r}4.9 \\
\pm 0.3\end{array}$ & $\begin{array}{r}5.3 \\
\pm 0.3\end{array}$ \\
\hline DL Vir A & & $\begin{array}{r}6.227 \\
\pm 0.009\end{array}$ & $\begin{array}{r}1970.001 \\
\pm 0.027\end{array}$ & $\begin{array}{r}0.491 \\
\pm 0.009\end{array}$ & $\begin{array}{r}185.3 \\
\pm 1.5\end{array}$ & $\begin{array}{r}-22.2 \\
\pm 0.1\end{array}$ & $\begin{array}{r}18.3 \\
\pm 0.2\end{array}$ \\
\hline HA 6469 A & McA 47 & $\begin{array}{r}5.527 \\
\pm 0.002\end{array}$ & $\begin{array}{r}1980.836 \\
\pm 0.005\end{array}$ & $\begin{array}{r}0.680 \\
\pm 0.005\end{array}$ & $\begin{array}{r}219.6 \\
\pm 0.8\end{array}$ & $\begin{array}{r}-3.2 \\
\pm 0.1\end{array}$ & $\begin{array}{r}18.4 \\
\pm 0.2\end{array}$ \\
\hline HR $6497 \mathrm{~A}$ & & $\begin{array}{r}3.287 \\
\pm 0.020\end{array}$ & $\begin{array}{r}1975.824 \\
\pm 0.010\end{array}$ & $\begin{array}{r}0.398 \\
\pm 0.010\end{array}$ & $\begin{array}{r}47.6 \\
\pm 1.4\end{array}$ & $\begin{array}{r}-14.3 \\
\pm 0.2\end{array}$ & $\begin{array}{r}17.7 \\
\pm 0.3\end{array}$ \\
\hline HR $6697 \mathrm{~A}$ & McA $\mathbf{5 0}$ & $\begin{array}{r}2.414 \\
\pm 0.004\end{array}$ & $\begin{array}{r}1989.508 \\
\pm 0.023\end{array}$ & $\begin{array}{r}0.443 \\
\pm 0.020\end{array}$ & $\begin{array}{r}133.9 \\
\pm 4.3\end{array}$ & $\begin{array}{r}-33.0 \\
\pm 0.2\end{array}$ & $\begin{array}{r}11.3 \\
\pm 0.3\end{array}$ \\
\hline$\psi$ SgI A & $\begin{array}{l}\text { ADS } 12214 \\
\text { B } 430\end{array}$ & $\begin{array}{r}20.028 \\
\pm 0.078\end{array}$ & $\begin{array}{r}1975.209 \\
\pm 0.080\end{array}$ & $\begin{array}{r}0.511 \\
\pm 0.015\end{array}$ & $\begin{array}{r}9.7 \\
\pm 9.7\end{array}$ & $\begin{array}{r}-28.0 \\
\pm 0.2\end{array}$ & $\begin{array}{r}14.2 \\
\pm 0.3\end{array}$ \\
\hline HD 202908B & $\begin{array}{l}\text { ADS } 14839 \\
\text { Bu } 163\end{array}$ & $\begin{array}{l}77.2 \\
\text { fixed }\end{array}$ & $\begin{array}{r}1987.067 \\
\pm 0.039\end{array}$ & $\begin{array}{r}0.866 \\
\pm 0.050\end{array}$ & $\begin{array}{r}171.3 \\
\pm 1.2\end{array}$ & $\begin{array}{r}5.2 \\
\pm 1.1\end{array}$ & $\begin{array}{r}13.0 \\
\pm 0.3\end{array}$ \\
\hline HD $203345 A$ & $\begin{array}{l}\text { ADS } 14893 \\
\text { A } 617\end{array}$ & $\begin{array}{r}6.053 \\
\pm 0.002\end{array}$ & $\begin{array}{l}1991.81 \\
\pm 0.002\end{array}$ & $\begin{array}{r}0.793 \\
\pm 0.003\end{array}$ & $\begin{array}{r}190.8 \\
\pm 0.6\end{array}$ & $\begin{array}{r}-19.0 \\
\pm 0.1\end{array}$ & $\begin{array}{r}19.9 \\
\pm 0.2\end{array}$ \\
\hline
\end{tabular}




\section{INDIVIDUAL SYSTEMS}

The systems in Table 2 are discussed, some more extensively than others.

13 Ceti = ADS 490: From an analysis of its visual orbit and parallax, Gatewood \& Behall (1975) suggested that this triple-star system is overluminous when compared to the empirical mass-luminosity relation. The visual orbital elements have been signigicantly improved by Hartkopf, McAlister, \& Franz (1989), and new spectroscopic results that include the spectroscopic detection of the visual secondary, have been given by Duquennoy \& Mayor (1991). My spectroscopic observations began in 1976 and now cover 2 orbital cycles. Spectroscopic elements for component B are given in Table 2 and are in excellent agreement with the visual elements. From the visual inclination of $49^{\circ}$ and the linear and angular separations, the orbital parallax is $0 " .047$, significantly less than the trigonometric value of 0.060 found by Gatewood \& Behall. The $M_{v}$ 's are 3.9 and $4.8 \mathrm{mag}$ for the F7 V star and the G4 V star, respectively. The resulting total mass is $2.83 \mathcal{M}_{\odot}$, and thus, the system is not overluminous. Although the inclination of the 2-day short-period orbit can not be determined directly, an observed $\mathrm{v} \sin \mathrm{i}$ of $24 \mathrm{~km} / \mathrm{s}$ for the $\mathrm{F} 7 \mathrm{~V}$ star and assumed radii of 1.1 to $1.5 \mathrm{R}_{\odot}$ result in an inclination of $65^{\circ}$ to $41^{\circ}$ and suggest that the orbits may be close to coplanar. If $i_{s}=50^{\circ}$, The F7 V star has a mass of $1.24 \mathcal{M}_{\odot}$ while the mass of the unseen secondary, presumably an $\mathrm{M}$ dwarf, is $0.5 \mathcal{M}_{\odot}$. The mass of the G4 V star is $1.09 \mathcal{M}_{\odot}$.

HR 266 = ADS 784: This early-type system has orbital periods of 4.2 days, 4.8 years, and 84 years. The intermediate-period system is a spectroscopic and speckle-astrometric binary. All three orbits may be coplanar. An extensive discussion of this complex system has just been published (Cole et al. 1992).

31 Ari $=$ HR 763 = McA 7: This system shows the complementary nature of spectroscopy and speckle interferometry in a slightly different light. However, the duplicity of 31 Ari was first detected by a lunar occultation (Africano et al. 1978) that also indicated that the two stars have similar luminosities. The second spectroscopic observation was obtained at a double-lined phase but the nearly equal line strengths of the components initially made the identification of the components quite difficult. In addition, the line doubling occurred for only a short period of time roughly every 2 years. It wasn't until a preliminary speckle orbit with a period of 3.8 years was determined that the correct orbital period of 1.9 years was identified from the spectroscopic observations. Since the system has a very eccentric orbit, the lines of the components are blended except for phases near the nodal passages. As expected, the minimum masses are nearly identical, $0.72 \pm 0.01 \mathcal{M}_{\odot}$. From the spectroscopic and preliminary speckle orbital elements, the masses are $1.05 \mathcal{M}_{\odot}$ each and the orbital parallax is $0^{\prime \prime} .031$, in agreement with the trigonometric parallax of $0^{\prime \prime} .035 . M_{v}=3.9 \mathrm{mag}$ for each component.

$\tau$ Per: Recently Griffin et al. (1992) have presented an extensive analysis of this composite eclipsing system and included a new orbital solution. My orbit is in excellent agreement with theirs. From my red wavelength spectra I find 
a spectral type of G8 III for the late-type star that confirms the revised type suggested by Griffin et al.

Capella: Accurate velocities of the hotter broad-lined star remain elusive. From 9 such velocities, I find a mass ratio of $1.060 \pm 0.016$ and masses of 2.64 $\pm 0.03 \mathcal{M}_{\odot}$ and $2.49 \pm 0.03 \mathcal{M}_{\odot}$ for the K0 III and G1 III, respectively.

$\mu$ Ori $=$ ADS 4617: $\quad$ My velocities and those of Abt, Sanwal, \& Levy (1980) have been used to determine the long-period orbit of the Am star. The recent visual orbital elements of Heintz (1989) are in good agreement.

$1 \mathrm{Gem}=$ Kui 23: $\quad$ My velocities and those of Scarfe (private communication) have been used to determine the long-period orbit of the $\mathrm{K}$ giant (Several other extensive data sets are available). The visual orbital elements of Heintz (1986) are in good agreement. The combination of the elements leads to an orbital parallax of 0 ".021 and for the K1 III component a mass of $2.1 \mathcal{M}_{\odot}$.

$\gamma$ Gem: Kamper \& Beardsley (1987) determined a combined astrometricspectroscopic solution for this system. My spectroscopic observations cover two periastron passages and by themselves result in slightly more accurate elements. Tomkin (private communication) obtained observations at a wavelength of 8900 $\AA$ but was unable to detect the secondary.

$63 \mathrm{Gem}=$ McA 30 Aa: Like 31 Ari this system was found to be an occultation binary (Eitter \& Beavers 1977) and the visual pair has been resolved with speckle interferometry. Lines of all three stars are visible in my red spectrograms. The short-period pair have slightly stronger and broader lines.

$\eta$ Vir = McA 37: Hartkopf et al. (1992) have just published an analysis of this early A-star system. It is uncertain whether the visual secondary has been detected in the spectrum.

DL Vir $=$ HD 120901/2: The system is composite and contains a shortperiod eclipsing pair. The long-period system remains unresolved but is thought to be just at the limit of resolution for speckle observations with a 4-m telescope.

HR 6469 = McA 47: Extensive spectroscopic, speckle, and photometric observations have been obtained of this composite eclipsing triple system. It is extensively discussed in a separate paper at this meeting (Scarfe et al. 1992).

HR 6497: This system is composite and consists of a pair of early-A stars and a $\mathrm{K}$ giant. So far it has not been resolved by speckle interferometry. The elements of Table 2 differ somewhat from those listed in the catalog of Batten et al. (1989).

HR 6697 = McA 50: This nearby dwarf system is double lined and also has been resolved by speckle interferometry. A joint paper is in preparation.

$\psi \mathbf{S g r}=$ HR $7292=\operatorname{ADS} 12214: \quad$ This system is of particular interest because it is one of the few (others are $\tau$ Per, Capella, 1 Gem, DL Vir, HR 6497, $\phi \mathrm{Cyg}$, and $\beta$ Cap) that contains an undisturbed giant for which an accurate 
mass can eventually be obtained. The system has also been resolved by the lunar occultation technique (Schmidtke, private communication), so an angular diameter of the late-type giant may also be determined. At red wavelengths, the second A-type star is very difficult to detect. After subtracting the late-type giant's spectrum, the residual spectrum shows weak lines of both late A-type stars.

HD 202908 = ADS 14839: This system consists of three similar solartype dwarfs. With a long period of about 77 years, my demise will almost certainly occur before I observe a full orbital cycle, but since the long-period pair recently went through nodal and periastron passage, the most interesting part of the spectroscopic orbit will soon be covered.

HD $203345=$ ADS 14893: This system also consists of three roughly solartype dwarfs. Several nodal passages have been covered and the long-period orbit is now well determined.

\section{PROPERTIES OF MULTIPLE SYSTEMS}

Over 10 years have passed since my summary on the properties of close multiple stars (Fekel 1981a). I am now in the process of collecting additional data on close multiple systems to update statistics on period ratios, mass ratios, the percentage of non-coplanar multiple systems, and other properties of such systems that may be useful for theoretical comparisons.

\section{ACKNOWLEDGMENTS}

It is a pleasure to acknowledge David S. Evans who sparked my interest in multiple stars nearly two decades ago. I also wish to thank Claud Lacy for sharing telescope time during the McDonald Observatory years and providing the initial version of the reduction program. The patience and data-reduction support of Daryl Willmarth and Jeannette Barnes of KPNO are greatfully acknowledged. A number of the systems listed in the tables are being observed spectroscopically in collaboration with Colin Scarfe, Jos Tomkin, and Roger Griffin, who have provided some data in advance of publication. The invaluable collaboration of Hal McAlister and Bill Hartkopf as well as others of their speckle group is gratefully acknowledged. This research has been supported in part by grants from NSF and the Vanderbilt Research Council.

\section{REFERENCES}

Abt, H.A., Sanwal, N. B., \& Levy, S.G. $1980, A p J S, 43,549$

Africano, J., Evans, D., Fekel, F., Smith, B., \& Morgan, C. 1978, $A J, 83,1100$

Batten, A.H., Fletcher, J. M., \& MacCarthy, D. G. 1989, PDAO, 17, 1

Batten, A.H., Morbey, C.L., Fekel, F.C. \& Tomkin, J. 1979, PASP, 91, 304

Cole, W., Fekel, F., Hartkopf, W., McAlister, H., \& Tomkin, J. 1992, AJ, 103, 1357

Duquennoy, A. \& Mayor, M. 1991, A\&A, 248, 485

Eitter, J.J. \& Beavers, W.I. 1977, ApJS, 34, 493

Evans, D.S. \& Fekel, F.C. 1979, $A p J, 228,497$ 
Fekel, F.C. $1975, A J, 80,844$

Fekel, F.C. 1980, PASP, 92, 785

Fekel, F.C. $1981 \mathrm{a}, A p J, 246,879$

Fekel, F.C. $1981 b, A p J, 248,670$

Fekel, F.C. \& Bopp, B.W. 1977, PASP, 89, 216

Fekel, F.C. \& Scarfe, C.D. 1986, $A J, 92,1162$

Fekel, F.C. \& Tomkin, J. 1982, $A p J, 263,289$

Fekel, F.C., Bopp, B.W., \& Lacy C. 1978, $A J, 83,1445$

Gatewood, G. \& Behall, A.L., 1975, $A J, 80,1065$

Griffin, R.E.M., Schroder, K.-P., Misch, A., \& Griffin, R. F. 1992, A\&A, 254, 289

Hartkopf, W.I., McAlister, H.A., \& Franz, O. G., 1989, AJ, 98, 1014

Hartkopf, W.I., McAlister, H.A., Yang, X., \& Fekel, F.C. 1982, AJ, 103, 1976

Heints, W.D. 1986, $A \& A S, 65,411$

Heints, W.D. 1989, PASP, 101, 510

Kamper, K.W. \& Beardsley, W.R. 1987, $A J, 94,1302$

Latham D. \& Stefanik, R. 1992, in Reports on Astronomy, IAU Trans. XXIB, in press

Pearce, J.A. 1957, Trans. IAU, 9, 441

Scarfe, C.D., Barlow, D.J., McAlister, H.A., Hartkopf, W.I., Fekel, F.C., Rees, R., Lyons, R.W., \& Bolton, C.T. 1992, Complementary Approaches to Double and Multiple Star Research, Proc. IAU Colloquium 135, in press

Strassmeier, K.G. \& Fekel, F.C. 1990, $A \mathcal{G} A, 230,389$

Tomkin, J., McAlister, H.A., Hartkopf, W.I., \& Fekel, F.C. 1987, AJ, 93, 1236

Van Biesbroeck, G. 1974, ApJS, 23, 413

Vogt, S.S., Tull, R.G., \& Kelton, P. 1978, Appl. Optics, 17, 574

Willmitch, T.R. 1989, Master's thesis, Vanderbilt University

Willmitch, T.R. \& Fekel, F.C. $1990, A J, 99,373$

\section{DISCUSSION}

VAN DESSEL: You mentioned Capella, saying that the data about the system are still unsatisfactory. I'm rather surprised about this given the long history of studies that have been going on, I would even ask you if you do not find it discouraging?

FEKEL: It is the semi-amplitude of the rapidly rotating hot star that remains a problem. However, I believe that current instruments and data reduction techniques will provide definitive results in the near future.

SCARFE: In HR 5472 we also found the inner eccentricity larger that that for the outer one. The period ratio is 30 in that case.

ABT: You have seen statistics on the frequencies of triples and quadruples by the Geneva group and us. Are you collecting data to modify those statistics significantly?

FEKEL: Yes, there is now a significantly increased number of systems with which a new study can be done. As a result, I have begun a new analysis. Preliminary results suggest that the numbers are similar.

EVANS: Do the period ratios in hierarchical systems show about the same distribution as you found a number of years ago?

FEKEL: Yes. 